Research Article

\title{
Diet Quality and Its Relationship with Antioxidant Status in Patients with Rheumatoid Arthritis
}

\author{
Anna Prescha $\mathbb{D}^{1},{ }^{1}$ Katarzyna Zabłocka-Słowińska ${ }^{(D)},{ }^{1}$ Sylwia Płaczkowska, ${ }^{2}$ Daiva Gorczyca, ${ }^{3}$ \\ Anna Luczak, ${ }^{4}$ Marcelina Majewska, ${ }^{5}$ and Halina Grajeta ${ }^{1}$ \\ ${ }^{1}$ Department of Food Science and Dietetics, Wrocław Medical University, Borowska 211, 50-556 Wrocław, Poland \\ ${ }^{2}$ Diagnostics Laboratory for Teaching and Research, Wrocław Medical University, Borowska 211, 50-556 Wrocław, Poland \\ ${ }^{3} 3 \mathrm{rd}$ Department and Clinic of Paediatrics, Immunology and Rheumatology of Developmental Age, Wrocław Medical University, \\ Koszarowa 5, 51-149 Wroctaw, Poland \\ ${ }^{4}$ Department and Clinic of Rheumatology and Internal Medicine, Wrocław Medical University, Borowska 213, \\ 50-556 Wrocław, Poland \\ ${ }^{5}$ Student Scientific Club Food Science and Dietetics, Wrocław Medical University, Wrocław, Poland
}

Correspondence should be addressed to Anna Prescha; anna.prescha@umed.wroc.pl

Received 14 December 2017; Revised 11 February 2018; Accepted 21 February 2018; Published 5 April 2018

Academic Editor: Steven McAnulty

Copyright (C) 2018 Anna Prescha et al. This is an open access article distributed under the Creative Commons Attribution License, which permits unrestricted use, distribution, and reproduction in any medium, provided the original work is properly cited.

\begin{abstract}
A direct contribution towards destructive, proliferative synovitis in rheumatoid arthritis (RA) has been attributed to reactive oxygen species action. Some nutrients are considered to be capable of improving the oxidant/antioxidant status in RA; however the impact of diet composition on the antioxidant capacity of serum has not yet been studied in this disease. The aim of the study was to assess the relationship between diet quality and antioxidant status in patients with RA and healthy controls. Nutritional assessment was performed, and antioxidant status in serum, without and with deproteinization (TAS and DSAS, resp.), was determined in 82 RA and 87 healthy subjects. The diet of the RA group was low-energy and imbalanced. TAS and DSAS were significantly lower in RA patients than in controls. Antioxidant status significantly correlated with the supply of foods and nutrients influencing antioxidant and anti-inflammatory defense in RA; however, in this group, TAS was more sensitive to diet than DSAS. In healthy subjects, the nonprotein pool of serum antioxidants was more tightly linked to diet. These outcomes indicate the need to monitor diet quality of patients with RA and the usefulness of TAS measurements in this monitoring.
\end{abstract}

\section{Introduction}

Rheumatoid arthritis (RA) is a chronic inflammatory autoimmune disease, causing destruction of the joints, which consequently leads to disability and may also affect the life span [1]. A direct contribution towards destructive, proliferative synovitis in RA has been attributed to reactive oxygen species action [2,3]. Markers of oxidative stress in the organism, such as blood and urine lipid peroxidation products, levels of reactive oxygen and nitrogen species, and total oxidant status, all increase in patients suffering from this disease [4-7]. Oxidative stress affects extracellular antioxidant concentrations, as well as the antioxidant enzyme activities measured in whole blood and serum of RA patients [8-11]. The total serum antioxidant status in RA, measured using different methods, has been found to be lower than those in healthy subjects. The levels of antioxidants in the blood and total antioxidant status negatively correlate with disease activity and duration; moreover, a low concentration of antioxidant components in the blood has been recognized as a risk factor for RA $[4,12,13]$.

Several studies have shown that an improvement in total antioxidant/oxidant status and mitigation of disease activity could be attained by antioxidant vitamins, polyphenols, and selenium supplementation at relatively high doses, although this high intake was not reflected in the concentration of those antioxidants in the blood of the patients $[5,14,15]$. The intake of selected dietary antioxidants (tocopherols, 
carotenoids, vitamin $\mathrm{C}$, and selenium) was not found to correlate with their serum level in RA patients either, and furthermore, oxidative stress as measured by MDA level was not affected by the intake of these compounds [16]. As diet supplies various compounds of antioxidant activity (including polyphenols) and those acting synergistically to antioxidants, measurements of selected dietary compounds may not reflect the total impact of diet on antioxidant/oxidant status. Moreover, in response to oxidative stress, adaptive mechanisms in the organism are initiated, which are considered to contribute to the misrepresentation of dietary antioxidant effects in the body [6]. The relationship between serum total antioxidant status (TAS) and the quality and composition of the diet has not yet been studied in RA patients. Recently, it has been demonstrated that diet quality may contribute to the course and activity of RA [17]. Evaluation of diet quality and its relationship with antioxidant status in patients with RA may help indicate dietary habits and nutrient intakes relevant to the improvement of antioxidant defense, and thereby to the mitigation of symptoms associated with RA [14].

A number of methods are used to measure serum antioxidant capacity as a marker of the condition of the antiradical defense system. Among them, a method with 2,2' -azinobis(3-ethylbenzothiazoline-6-sulfonic acid) diammonium salt (ABTS reagent) has been established (Randox method). The ABTS test measures the ability of nonenzymatic serum components to reduce the radical cation of ABTS $[18,19]$. In human plasma, TAS is mainly conditioned by albumin (representing $43-53 \%$ of the total value) and uric acid (33\%). It has been shown that TAS additionally includes ascorbic acid, $\alpha$-tocopherol, and bilirubin activity [20]. The rheumatoid cachexia occurring in RA patients may affect protein antioxidant level in the serum and thereby distort assessment of the impact of dietary components on antioxidant status [21]. Therefore, in addition to TAS determination, serum antioxidant status as measured after deproteinization in organic solutions (acetonitrile and methanol) using 2,2' -diphenyl-1picrylhydrazyl (DPPH) stable radical may be proposed as potentially useful in the assessment of diet relation to antioxidant status in RA. DSAS method has been shown to be sensitive to the negligible differences in serum level of ascorbic acid, quercetin, and uric acid in healthy subjects [22]. We hypothesize that measurements of deproteinized serum antioxidant status (DSAS) may highlight the antiradical properties of hydrophilic and lipophilic nutrients; hence, we can better visualize the relationship of diet with the antioxidant status of RA patients.

The aim of this study was to assess diet quality and estimate the impact of diet composition on the antioxidant status, as measured in serum without and with deproteinization (TAS and DSAS, resp.), of patients with RA and healthy subjects.

\section{Patients and Methods}

Eighty-two patients with RA and 87 healthy controls were included in the study. Participants were recruited via the outpatient clinic of the Department of Rheumatology and
Internal Medicine, Wrocław Medical University, and all patients with RA fulfilled the American College of Rheumatology criteria. The control group consisted of healthy people recruited from public offices and Wrocław 3rd Age Universities. Exclusion criteria for the control group were proinflammatory diseases and mental health issues. The study protocol was approved by the Wrocław Medical University Ethics Board (consent no. KB-390/2012). All patients gave written informed consent.

The patients with RA underwent clinical examination by a rheumatologist, and the following data were collected: age when consent for the study was given, duration of disease, number of swollen joints, number of painful joints, the presence of rheumatoid factor (RF), anticitrullinated protein antibodies (ACPA), the Disease Activity Score of 28 joints (DAS 28), and pharmacological treatment. In both RA and control groups, body mass index (BMI) was measured, and data on declared smoking status were collected.

For diet quality assessment, the study used 3-day food records and a dietary habits questionnaire developed at the Department of Food Science and Dietetics, Wrocław Medical University [23]. The Album of Photographs of Food Products and Dishes was used to estimate food portion sizes [24]. The questionnaire consisted of 106 questions concerning the consumption of food groups, as well as individual foods within the groups calculated in portions per unit of time. The calculation of the composition of daily food rations was made using the computer program Diet 5.0 developed by the National Food and Nutrition Institute in Warsaw [25].

Blood samples were collected from all subjects under fasting conditions, and TAS was determined by the spectrophotometric method with 2,2' -azino-bis(3-ethylbenzothiazoline6-sulfonic acid) diammonium salt (ABTS reagent, Randox Total Antioxidant Status, Randox Laboratories Ltd., cat. no. NX 2332) using autoanalyzer Konelab 20i (Thermo Fisher Scientific, USA) [20]. DSAS was also measured spectrophotometrically with DPPH radical using Spectronic GENESYS $6 \mathrm{UV}$-visible spectrophotometer (Thermo Electron Corporation, USA) [22]. In both methods, antioxidant status was expressed in Trolox equivalents. Serum albumin level was determined as a coloured complex with bromocresol green, and uric acid-based on oxidation with uricase. These measurements were performed with the autoanalyzer Konelab 20i.

Statistical calculations were performed using Statistica StatSoft 12.0. Pearson's $\chi^{2}$ test was used for assessment of differences in qualitative variables between groups. The correlation of antioxidant status with nutrient intake and frequency of food consumption was assessed in both RA and control groups, further divided into current smoker and nonsmoker (former and never smoker) subgroups. Depending on the distribution of variables, either Student's $t$-test or the MannWhitney $U$ test was used for group comparisons, and Pearson or Spearman correlation analysis was performed for measurements of association between variables.

\section{Results}

The baseline characteristics of the patients and control subjects are summarised in Table 1. The RA group consisted of 
TABLE 1: Group characteristics.

\begin{tabular}{|c|c|c|c|}
\hline Parameter & RA group $(n=82)$ & Control group $(n=87)$ & $p$ value \\
\hline \multicolumn{4}{|l|}{ Sex of subjects, $n$ (\% of group) } \\
\hline Female & $61(74.4 \%)$ & $50(57.5 \%)$ & \multirow{2}{*}{0.0012} \\
\hline Male & $21(25.6 \%)$ & $37(42.5 \%)$ & \\
\hline Age (years), median (range) & $54(20-82)$ & $53(25-78)$ & NS \\
\hline \multicolumn{4}{|l|}{ BMI $\left(\mathrm{kg} / \mathrm{m}^{2}\right), n(\%)$} \\
\hline$<18.5$ & $2(2.4 \%)$ & $2(2.3 \%)$ & \multirow{3}{*}{ NS } \\
\hline $18.5-24.9$ & $36(43.9 \%)$ & $29(33.3 \%)$ & \\
\hline$\geq 25$ & $44(53.7 \%)$ & $56(64.4 \%)$ & \\
\hline \multicolumn{4}{|l|}{ Cigarette smoking, $n(\%)$} \\
\hline Current smoker & $22(26.8 \%)$ & $31(35.6 \%)$ & \multirow{3}{*}{0.023} \\
\hline Former smoker (cessation $\geq 1$ year) & $29(35.4 \%)$ & $38(43.7 \%)$ & \\
\hline Never smoker & $31(37.8 \%)$ & $18(20.7 \%)$ & \\
\hline Albumin (g/dL), median (range) & $3.93(2.57-5.70)$ & $4.23(2.85-5.42)$ & $<0.000001$ \\
\hline Uric acid (g/dL), median (range) & $4.3(1.5-9.1)$ & $5.2(3.0-8.8)$ & NS \\
\hline Time from RA onset (years), median (range) & $8.5(0.2-50)$ & - & - \\
\hline $\mathrm{RF}+($ cutoff $20 \mathrm{IU} / \mathrm{mL}), n(\%)$ & $53(64.6 \%)$ & - & - \\
\hline $\mathrm{ACPA}+($ cutoff $25 \mathrm{U} / \mathrm{mL}), n(\%)$ & $41(50.0 \%)$ & - & - \\
\hline Number of swollen joints, median (range) & $4(0-24)$ & - & - \\
\hline DAS 28 , median (range) & $5.01(1.49-8.49)$ & - & - \\
\hline Treatment & & & - \\
\hline Methotrexate & $46(56.1 \%)$ & - & - \\
\hline Other nonbiologic DMARDs & $33(40.2 \%)$ & - & - \\
\hline Anti-TNF therapy & $23(28.0 \%)$ & - & - \\
\hline Steroids & $62(75.6 \%)$ & - & - \\
\hline
\end{tabular}

$n$ : number of subjects; NS: not significant; Anti-TNF, anti-tumour necrosis factor; BMI: body mass index; RF: rheumatoid factor; ACPA: anti-citrullinated protein antibody; DAS 28: Disease Activity Score of 28 joints; DMARDs: disease-modifying antirheumatic drugs.

a higher percentage of female patients and a lower percentage of current smokers in comparison with the control group $(p<0.02)$. More than half of the RA and control subjects were overweight or obese. Significantly lower $(p<0.000001)$ concentration of serum albumin was found in RA patients in comparison to control subjects; however, the median of albumin value in the RA group did not indicate protein malnutrition $(<3.5 \mathrm{~g} / \mathrm{dL})$. For the majority of patients, RA therapy included steroids and also methotrexate.

The assessment of dietary intake using food records showed that the diet of subjects in both groups was lowenergy and provided an insufficient amount of fat; moreover, a significantly lower intake of these nutrients was observed in the RA than in the control group ( $p<0.002$, Figure 1$)$. In both groups, an insufficient intake of long chain polyunsaturated fatty acids (LCPUFA) and vitamin E was shown. The amount of dietary folate and vitamin $\mathrm{D}$ was also low, especially in the RA group ( $p=0.02$ and $p=0.00008$, resp.). An excessive supply of sodium, phosphorus, iron, copper, and manganese and a very low intake of potassium and calcium were observed in both groups (Figure 2).

Diet quality assessment also included an analysis of food consumption frequencies in both groups. As the comparison of dietary habits between RA and the control group generated numerous data, only the consumption frequencies of food groups rich in antioxidants were presented in Table 2. It has been shown that levels of consumption of vegetables, fruits, and fruit and vegetable juices did not differ significantly between groups and in the majority of subjects did not exceed 2 servings per day (Table 2). Chocolate, dried fruits, and tea were consumed significantly more often in the RA group $(p<0.02)$, whereas whole-grain cereal products, coffee, herbs, and spices were eaten more rarely $(p<0.02)$. Around half of the subjects in both groups consumed vegetable oils irregularly.

Measurements of serum antioxidant status showed significantly lower values of TAS, as measured using ABTS reagent, in patients with $\mathrm{RA}$ when compared to the control group (median 1.47 versus $1.72 \mathrm{mM}$ Trolox; $p=0.031$, Table 3). DSAS, measured using the DPPH method, was also significantly lower in RA patients (median 174.3 versus 206.4, $p=0.027$ ). A significant correlation between TAS and DSAS values was observed in both groups; however, this relationship was stronger in RA patients $(r=0.56, p=0.019)$. TAS correlated positively with serum albumin concentration in the control group $(r=0.34, p<0.000001)$, while in the RA group, a significant correlation $(r=0.23, p=0.027)$ was found only in subjects with an albumin level equal to, or over, the median value $(3.93 \mathrm{~g} / \mathrm{dL})$. In contrast, DSAS correlated negatively $(r=-0.21, p=0.049)$ with albumin level only in 


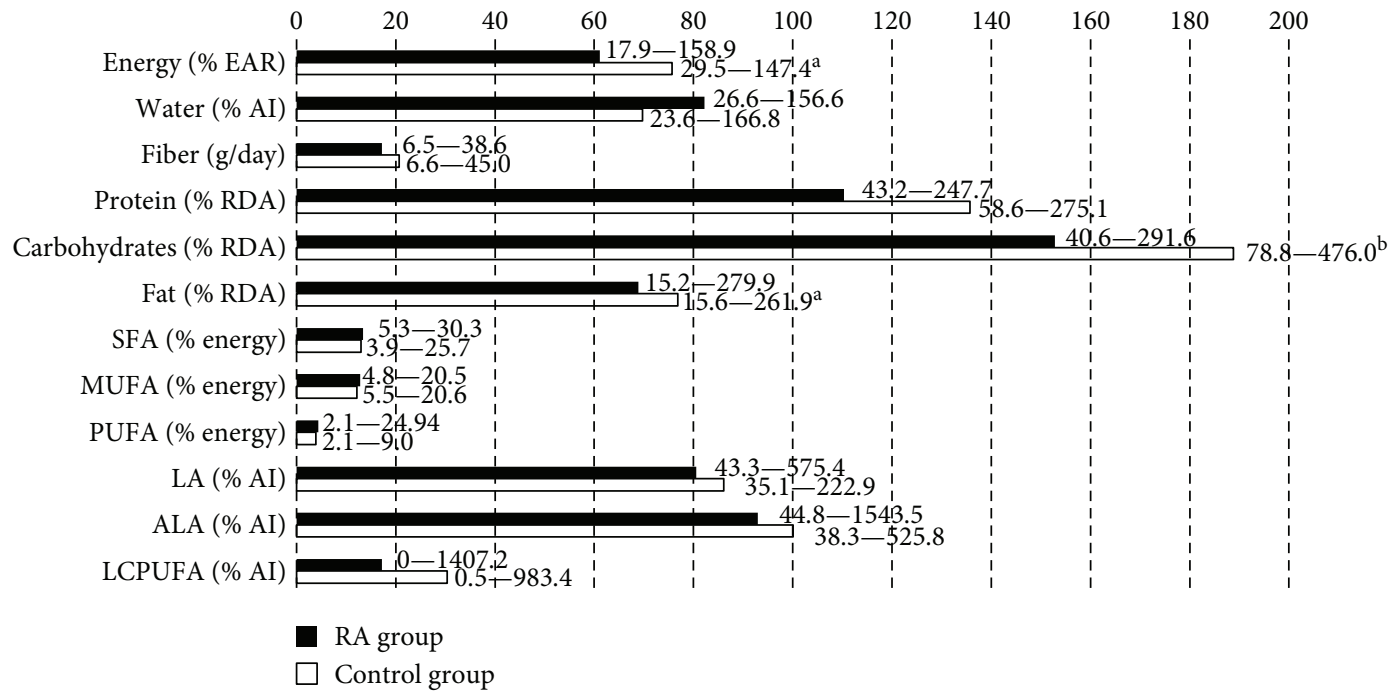

Figure 1: Macronutrient intake and dietary fat components in RA and control groups (\% of recommendations) - median and range. SFA: saturated fatty acids; MUFA: monounsaturated fatty acids; PUFA: polyunsaturated fatty acids: LA: linoleic acid; ALA: $\alpha$-linolenic acid; LCPUFA: long chain polyunsaturated fatty acids; EAR: estimated average requirement; AI: adequate intake; RDA: recommended dietary allowances. Statistically significant differences ( $p$ value): ${ }^{\mathrm{a}}<0.005,{ }^{\mathrm{b}}<0.0001$.

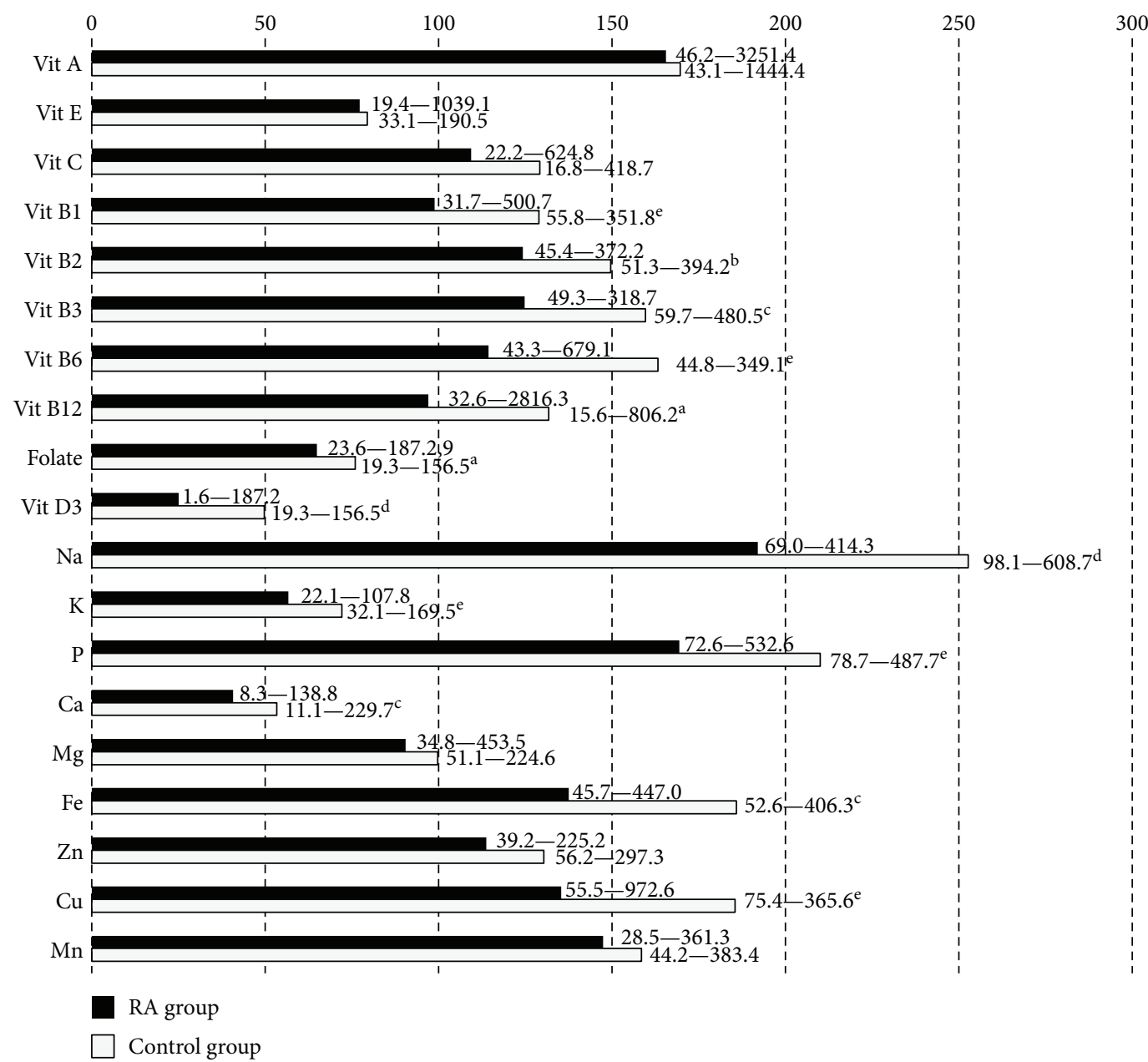

FIgURE 2: Micronutrient intake in RA and control groups (\% of recommendations) - median and range. The values expressed in \% RDA, except for vitamin $\mathrm{E}, \mathrm{Na}$, and $\mathrm{K}(\% \mathrm{AI})$ and $\mathrm{Mn}$ (mean $\mathrm{AI}$ in European countries). Statistically significant differences $\left(p\right.$ value): ${ }^{\mathrm{a}}<0.05$, ${ }^{\mathrm{b}}<0.01,{ }^{\mathrm{c}}<0.005,{ }^{\mathrm{d}}<0.001,{ }^{\mathrm{e}}<0.0001$. 
TABLE 2: Consumption of food sources of antioxidants.

\begin{tabular}{|c|c|c|c|c|}
\hline Food consumption & & RA (\% of group) & Control (\% of group) & $p$ value \\
\hline \multirow{3}{*}{ Whole-grain cereal products } & $\geq 3$ servings/day & 2.4 & 14.9 & \multirow{3}{*}{0.018} \\
\hline & 1-2 servings/day & 37.8 & 36.8 & \\
\hline & Irregularly & 59.8 & 48.3 & \\
\hline \multirow{3}{*}{ Vegetables } & $\geq 3$ servings/day & 34.1 & 29.9 & \multirow{3}{*}{ NS } \\
\hline & 1-2 servings/day & 58.5 & 63.2 & \\
\hline & Irregularly & 7.3 & 6.9 & \\
\hline \multirow{3}{*}{ Fruits } & $\geq 3$ servings/day & 23.2 & 26.4 & \multirow{3}{*}{ NS } \\
\hline & 1-2 servings/day & 65.9 & 62.1 & \\
\hline & Irregularly & 11.0 & 11.5 & \\
\hline \multirow{3}{*}{ Fruit and vegetable juices } & $\geq 3$ cups/day & 4.9 & 1.1 & \multirow{3}{*}{ NS } \\
\hline & 1-2 cups/day & 37.8 & 28.7 & \\
\hline & Irregularly & 57.3 & 70.1 & \\
\hline \multirow{3}{*}{ Nuts, seeds, and legumes } & $>5$ servings/week & 12.2 & 4.6 & \multirow{3}{*}{0.019} \\
\hline & 2-5 servings/week & 14.6 & 28.7 & \\
\hline & $\leq 1$ serving/week & 73.1 & 65.5 & \\
\hline \multirow{3}{*}{ Dried fruits } & $>5$ servings/week & 9.8 & 1.1 & \multirow{3}{*}{0.0011} \\
\hline & 2-5 servings/week & 22.2 & 6.9 & \\
\hline & $\leq 1$ serving/week & 70.7 & 92.0 & \\
\hline \multirow{3}{*}{ Chocolate } & $\geq 15 \mathrm{~g} /$ day & 14.6 & 6.9 & \multirow{3}{*}{0.0083} \\
\hline & $4-14$ g/day & 42.7 & 34.5 & \\
\hline & Irregularly & 48.7 & 58.6 & \\
\hline \multirow{3}{*}{ Tea } & $\geq 4$ cups/day & 25.6 & 12.6 & \multirow{3}{*}{0.000060} \\
\hline & $2-3$ cups/day & 57.3 & 39.1 & \\
\hline & $\leq 1$ cups/day & 17.1 & 48.3 & \\
\hline \multirow{3}{*}{ Coffee } & $\geq 4$ cups/day & 1.2 & 9.2 & \multirow{3}{*}{0.000052} \\
\hline & 2-3 cups/day & 13.4 & 47.1 & \\
\hline & $\leq 1$ cups/day & 85.4 & 43.7 & \\
\hline \multirow{3}{*}{ Vegetable oils } & $>1$ tablespoon/day & 7.3 & 12.6 & \multirow{3}{*}{ NS } \\
\hline & 0.5-1 tablespoon/day & 35.3 & 39.1 & \\
\hline & Irregularly & 57.3 & 48.3 & \\
\hline \multirow{3}{*}{ Herbs and spices } & $\geq 0.5$ teaspoon/day & 6.1 & 11.5 & \multirow{3}{*}{0.0043} \\
\hline & $<0.5$ teaspoon/day & 74.3 & 85.1 & \\
\hline & Irregularly & 19.5 & 3.4 & \\
\hline
\end{tabular}

NS: not significant.

subjects with an albumin level lower than $3.93 \mathrm{~g} / \mathrm{dL}$. Both parameters used for antioxidant status assessment positively correlated with serum uric acid concentration, whether in RA (TAS: $r=0.58, p=0.027$; DSAS: $r=0.39, p=0.017$ ) or in healthy subjects (TAS: $r=0.62, p=0.0011$; DSAS: $r=$ $0.27, p=0.031)$. Moreover, TAS level was negatively related to the number of swollen joints $(r=-0.37)$ and disease duration $(r=-0.25)$ in RA patients $(p<0.03)$.

The associations between diet composition and serum antioxidant status were significant in both studied groups. TAS values positively correlated, especially in the RA group $(r=0.21-0.87, p<0.04)$, with the supply of foods and nutrients considered important in antioxidant status maintenance (Table 4). A significant impact on TAS seemed to be attributed to the composition of dietary fat in RA patients.
Smoking status considerably influenced the correlation of TAS with vegetables, groats, chocolate, and Ca supply in the diet. Moreover, in the case of meat and fish consumption, we observed strong yet opposing effects on TAS in nonsmoking RA patients. In the control group, only the intake of total fat, monounsaturated fatty acids (MUFA), and vitamin A, as well as the n-6/n-3 fatty acid ratio, positively influenced TAS values. DSAS values positively correlated with the consumption of whole-grain bread and legumes in both groups. In the RA group, a positive correlation was also discovered for frequency of tea consumption, while in the control group, for frequency of apple consumption. A significant relationship between DSAS and intake of unsaturated fatty acid, dietary fiber, and vitamin $\mathrm{A}$, as well as $\mathrm{Fe}$ and $\mathrm{Cu}$, was found in the control group $(r=0.21-0.55, p<0.05)$, while in the case 
TABLE 3: Serum antioxidant capacity (TAS and DSAS) level and significant correlations with clinical parameters.

\begin{tabular}{|c|c|c|c|}
\hline & RA group & Control group & $p$ value \\
\hline \multicolumn{4}{|c|}{ Serum antioxidant capacity (mM Trolox) } \\
\hline TAS, median (range) & $1.47(1.03-1.86)$ & $1.72(1.33-2.14)$ & 0.031 \\
\hline DSAS, median (range) & $174.3(61.0-352.3)$ & $206.4(97.1-523.1)$ & 0.027 \\
\hline \multirow{2}{*}{ TAS/DSAS correlation ( $r$ values) } & 0.56 & - & 0.019 \\
\hline & - & 0.25 & 0.038 \\
\hline \multicolumn{4}{|c|}{ Significant correlation of TAS with clinical parameters ( $r$ values) } \\
\hline \multirow{2}{*}{ Albumin } & $0.23^{*}$ & - & 0.027 \\
\hline & - & 0.52 & $<0.000001$ \\
\hline \multirow{2}{*}{ Uric acid } & 0.58 & - & 0.027 \\
\hline & - & 0.62 & 0.0011 \\
\hline Number of swollen joints & -0.37 & - & 0.022 \\
\hline Time from RA onset & -0.25 & - & 0.027 \\
\hline \multicolumn{4}{|c|}{ Significant correlation of DSAS with clinical parameters ( $r$ values) } \\
\hline \multirow{2}{*}{ Albumin } & $-0.21^{* *}$ & - & 0.049 \\
\hline & - & 0.31 & 0.0042 \\
\hline \multirow{2}{*}{ Uric acid } & 0.39 & - & 0.017 \\
\hline & - & 0.27 & 0.031 \\
\hline
\end{tabular}

*Only in patients with albumin level $\geq 3.93$ (median value in RA group). ${ }^{* *}$ Only in patients with albumin level $<3.93$ (median value in RA group)

of vitamin $\mathrm{C}$, the correlation concerned the nonsmoker subgroup only.

\section{Discussion}

The assessment of diet quality based on nutrient intake indicates that the diet of the RA group was low-energy, and not well balanced. The insufficient intake of energy was not reflected in BMI values of the studied RA population since the majority of them were overweight or obese. This confirms previous findings that $\mathrm{BMI}$ is not a reliable parameter to detect malnutrition in RA, due to the abnormality of fat/ fat-free mass ratio as a result of RA cachexia [26, 27]. The impact of a low-energy diet on oxidant/antioxidant status has not yet been studied in RA or other autoimmune disorders. In overweight and normal-weight healthy individuals, as well as in subjects with metabolic syndrome, energy restriction is considered to contribute to oxidative stress reduction-however, this dietary modification needs to be accompanied by an adequate supply of essential nutrients $[28,29]$. In the RA patients recruited to this study, the low supply of energy was mainly due to insufficient fat intake, especially n-3 PUFA ( $\alpha$-linolenic acid and LCPUFA). The deficiency of these fatty acids is unfavourable in RA, because of the proven beneficial effects of n-3 PUFA in the improvement of disease activity, inflammatory, and oxidative markers [30, 31]. Sodium intake, which has been shown to promote Th17 cell-mediated inflammation, particularly in smoking subjects [32], was almost twice the RDA value in the studied RA group. The assessment of the dietary habits of RA patients revealed that the consumption of foods involved in antioxidant status maintenance, especially whole-grain cereals, fruits, and vegetables, was low. Generally, patients with RA were more likely to have poorer diet quality than do healthy subjects. Inadequate diet quality, assessed using Healthy Eating Index (HEI) 2010, was also observed in RA patients by Berube et al. [17] with a prevalence of low whole-grain and dairy food consumption.

An impairment of antioxidant defense in RA patients was also shown in our study. The TAS values were lower in the RA than in the healthy population, confirming the findings of other authors $[13,33]$. Likewise, the comparison of DSAS values between groups enabled us to detect lower antioxidant activity by nonprotein antiradicals in the RA group, when compared to the controls. In both RA and control groups, DSAS values comprised about $12 \%$ of Randox-TAS values, expressed as $\mathrm{mM}$ of Trolox equivalents in serum. According to the published data, the contribution of nonprotein antioxidants to serum TAS is higher and varies from 47 to $93 \%$ depending on the method used $[20,34]$. Both DPPH and ABTS tests measure the capacity of antioxidant compounds for scavenging stable free radicals; however, the substrates and environments of reaction differ between methods. Organic solvents used in the DPPH test (methanol and acetonitrile) might negatively affect antioxidant activity in comparison with solutions containing water [35].

Impaired antioxidant status in the RA group may be related to the loss of antioxidant components due to the neutralisation of radicals produced as a consequence of inflammation in the joints involved, and this may be also caused by an inadequate supply of antioxidant nutrients [36, 37]. Depletion of the antioxidant pool in RA may be also a consequence of therapy [38]. In the studied RA group, an inverse correlation of TAS with disease duration and number of swollen joints was shown. In published studies, a positive correlation between biomarkers of oxidative stress and RA disease severity was shown; hence, these findings suggest that TAS value might serve as a valuable marker in the assessment 
TABLE 4: TAS and DSAS correlation with food consumption and nutrient intake.

\begin{tabular}{lccc}
\hline & $\begin{array}{c}\text { RA } \\
\text { group }\end{array}$ & $\begin{array}{c}\text { Control } \\
\text { group }\end{array}$ & $p$ value \\
\hline $\begin{array}{l}\text { Significant correlation of TAS with food consumption/nutrient } \\
\text { intake ( } r \text { values) }\end{array}$ & $-0.76^{*}$ & & \\
Meat & $0.87^{*}$ & & 0.0012 \\
Fish & $0.73^{*}$ & & 0.0013 \\
Groats & $0.42^{* *}$ & & 0.0016 \\
Vegetables (total) & $0.85^{*}$ & & 0.011 \\
Leafy vegetables & $0.41^{* *}$ & - & 0.039 \\
Cruciferous vegetables & - & $-0.39^{* *}$ & 0.018 \\
Fruit and vegetable juices & 0.42 & & 0.0082 \\
Chocolate & $0.43^{* *}$ & & 0.0073 \\
\% energy from fat & & 0.27 & 0.033 \\
\% energy from LA & 0.22 & & 0.027 \\
\% energy from ALA & 0.39 & & 0.022 \\
\% energy from PUFA & 0.28 & & 0.037 \\
\% energy from MUFA & & 0.23 & 0.042 \\
\% energy from SFA & $-0.38^{* *}$ & & 0.0018 \\
n-6/n-3 fatty acid ratio & & 0.20 & 0.046 \\
\% RDA of vitamin E & 0.21 & & 0.035 \\
\% RDA of vitamin A & & 0.22 & 0.046 \\
\% retinol in vitamin A intake & & & 0.018 \\
\% RDA of vitamin B6 & 0.32 & & 0.021 \\
\% RDA of Ca & $0.40^{* *}$ & & 0.023
\end{tabular}

Significant correlations of DSAS with food consumption/nutrient intake ( $r$ values)

\begin{tabular}{lccc} 
Whole-grain bread & 0.28 & - & 0.036 \\
& - & 0.44 & 0.017 \\
Legumes & 0.24 & - & 0.019 \\
Tea & - & 0.24 & 0.039 \\
Apple & 0.31 & & 0.018 \\
EPA & & 0.31 & 0.028 \\
\% energy from ALA & & 0.25 & 0.032 \\
\% energy from MUFA & & 0.27 & 0.026 \\
\% RDA of vitamin C & -0.25 & 0.26 & 0.044 \\
\% RDA of vitamin A & - & $0.25^{*}$ & 0.041 \\
\% retinol in vitamin A intake & & 0.44 & 0.0026 \\
\% RDA of Fe & & 0.55 & 0.0012 \\
\% RDA of Cu & & 0.30 & 0.023 \\
Dietary fiber & & 0.21 & 0.043 \\
\hline
\end{tabular}

${ }^{*}$ Only nonsmokers. ${ }^{* *}$ Only smokers.

of redox status and RA progression $[39,40]$. The strong influence of endogenous antioxidant components, that is, albumin and uric acid, on the antioxidant status of serum without deproteinization observed in the control group was expressed to a lesser extent in the RA group. A strong relationship between TAS values and the concentration of uric acid levels in healthy subjects, as well as populations with different chronic diseases, has been previously shown in several studies [20,41]. More than half of the RA group were treated with methotrexate, which could affect the level of uric acid and hence deplete the pool of low-molecular-weight antioxidants in serum [38]. The uric acid determination performed in our study, however, did not reveal significant differences between groups $(p=0.062)$. As in the RA group, a significantly lower concentration of serum albumin was found than that in the controls, indicating enhanced protein catabolism related to inflammatory processes [21]; hence, the contribution of this macromolecule to the serum antioxidant pool seems to be weaker than that of other components. The considerable impact of the nonprotein constituents of the antioxidant pool is confirmed by a not particularly strong, yet significant, negative correlation between albumin and DSAS values in RA patients with low albumins, suggesting the compensative role of micronutrients in the antioxidant defense of patients suffering from protein disturbances.

The analysis of the relationships between TAS and diet composition carried out in this study suggests that fat components, especially total PUFA, SFA, and vitamin E, play an important role in the antioxidant defense of RA patients. Among antioxidant vitamins, tocopherols were found to be effective in the inhibition of joint destruction in the animal model [42]; however, in patients with RA, an improvement in oxidation status and total disease severity stage was only observed in combination with ascorbic acid and vitamin A [15]. Pyridoxine was the only water-soluble vitamin to enhance TAS in our study, which may confirm the benefits of supplementing this vitamin as a part of RA treatment [43]. The strong effects of meat and fish consumption on TAS in the RA group may be attributed to the fat composition of these foods and its impact on antioxidant and antiinflammatory status $[44,45]$. In addition to this finding, the significant effects on TAS noticed in the RA group related to the consumption of foods rich in antioxidants, for example, vegetables, especially leafy ones, chocolate, and groats, lead us to emphasize the important role of diet in the maintenance of the antioxidant defense of patients suffering from this autoimmune disease. The correlation of fruit juices consumption with TAS noticed in this population could result from the fructose rather than the antioxidant content in these foods, as it has been shown that fructose utilisation significantly influences the level of uric acid comprising an important part of the antioxidant pool in serum $[46,47]$.

Determination of DSAS was used in this work to assess the total activity of exogenous low-molecular-weight antioxidants, such as vitamins and polyphenols, as well as endogenous uric acid. This study revealed considerably less correlations of DSAS with nutrient intake and food consumption in the RA group than in controls. A positive correlation of the DSAS test with many dietary nutrients, including fatty acids, vitamins, and minerals, was observed in the control group. The effect of PUFA on TAS was not confirmed for DSAS in the RA group. This may result from the involvement of fatty acid metabolites in the modulation 
of macromolecular components of inflammation, such as cytokines, rather than the microcomponents of the serum antioxidant pool [48]. Moreover, a negative effect of vitamin C intake on DSAS was observed, albeit ascorbic acid has recently been shown to significantly reduce reactive oxygen and nitrogen species levels in individuals with RA [5]. The positive correlation between tea consumption and DSAS values may confirm the beneficial role of tea polyphenols in RA [49].

It should be noted that the relationship between antioxidant status and certain dietary components was influenced by smoking status, especially in the RA group, indicating the strong impact of this environmental factor on oxidant/ antioxidant ratio in RA. Significant depletion of antioxidant capacity has been previously shown in healthy smokers when compared to nonsmokers (a well-known factor) [50]. Moreover, in smokers suffering from RA, an increase of disease activity was observed [51].

\section{Conclusions}

The results of this study indicate the relationship between the serum antioxidant status of RA patients and the quality and composition of their diet. The disturbance of protein metabolism in RA seems to sensitize the antioxidant status of an affected organism to a diet which is imbalanced and poor in dietary antioxidants and anti-inflammatory agents.

We have shown the greater usefulness of TAS rather than DSAS measurements in the assessment of dietary impact on antioxidant capacity in RA patients; however, for healthy subjects, the nonprotein contribution in serum antioxidant capacity seems to be more sensitive to diet.

This study confirms the need to monitor the intake of nutrients involved in the antioxidant defense of patients with RA.

\section{Conflicts of Interest}

The authors declare that there is no conflict of interest regarding the publication of this paper.

\section{Acknowledgments}

This work was financially supported by the Wrocław Medical University (Grant no. ST-846).

\section{References}

[1] J. S. Smolen, F. C. Breedveld, G. R. Burmester et al., "Treating rheumatoid arthritis to target: 2014 update of the recommendations of an international task force," Annals of the Rheumatic Diseases, vol. 75, no. 1, pp. 3-15, 2015.

[2] I. B. McInnes and G. Schett, "The pathogenesis of rheumatoid arthritis," New England Journal of Medicine, vol. 365, no. 23, pp. 2205-2219, 2011.

[3] C. A. Hitchon and H. S. El-Gabalawy, "Oxidation in rheumatoid arthritis," Arthritis Research and Therapy, vol. 6, no. 6, pp. 265-278, 2004.

[4] A. Seven, S. Güzel, M. Aslan, and V. Hamuryudan, "Lipid, protein, DNA oxidation and antioxidant status in rheumatoid arthritis," Clinical Biochemistry, vol. 41, no. 7-8, pp. 538543, 2008.

[5] H. M. Khojah, S. Ahmed, M. S. Abdel-Rahman, and A. B. Hamza, "Reactive oxygen and nitrogen species in patients with rheumatoid arthritis as potential biomarkers for disease activity and the role of antioxidants," Free Radical Biology and Medicine, vol. 97, pp. 285-291, 2016.

[6] W. Łuczaj, E. Gindzienska-Sieskiewicz, I. Jarocka-Karpowicz et al., "The onset of lipid peroxidation in rheumatoid arthritis: consequences and monitoring," Free Radical Research, vol. 50, no. 3, pp. 304-313, 2016.

[7] O. Altindag, M. Karakoc, A. Kocyigit, H. Celik, and N. Soran, "Increased DNA damage and oxidative stress in patients with rheumatoid arthritis," Clinical Biochemistry, vol. 40, no. 3-4, pp. 167-171, 2007.

[8] S. Taysi, F. Polat, M. Gul, R. Sari, and E. Bakan, "Lipid peroxidation, some extracellular antioxidants, and antioxidant enzymes in serum of patients with rheumatoid arthritis," Rheumatology International, vol. 21, no. 5, pp. 200-204, 2002.

[9] S. Paredes, J. Girona, E. Hurt-Camejo et al., "Antioxidant vitamins and lipid peroxidation in patients with rheumatoid arthritis: association with inflammatory markers," The Journal of Rheumatology, vol. 29, no. 11, pp. 2271-2277, 2002.

[10] A. Kamanlı, M. Nazıroğlu, N. Aydılek, and C. Hacıevlıyagil, "Plasma lipid peroxidation and antioxidant levels in patients with rheumatoid arthritis," Cell Biochemistry and Function, vol. 22, no. 1, pp. 53-57, 2004.

[11] P. De Pablo, T. Dietrich, and E. W. Karlson, "Antioxidants and other novel cardiovascular risk factors in subjects with rheumatoid arthritis in a large population sample," Arthritis \& Rheumatism, vol. 57, no. 6, pp. 953-962, 2007.

[12] H. Serdar Öztürk, M. Y. Burak Çimen, Ö. BÖlgen Çimen, M. Kaçmaz, and Î. Durak, "Oxidant/antioxidant status of plasma samples from patients with rheumatoid arthritis," Rheumatology International, vol. 19, no. 1-2, pp. 35-37, 1999.

[13] S. Sarban, A. Kocyigit, M. Yazar, and U. E. Isikan, "Plasma total antioxidant capacity, lipid peroxidation, and erythrocyte antioxidant enzyme activities in patients with rheumatoid arthritis and osteoarthritis," Clinical Biochemistry, vol. 38, no. 11, pp. 981-986, 2005.

[14] M. Jalili, S. Kolahi, S. R. Aref-Hosseini, M. E. Mamegani, and A. Hekmatdoost, "Beneficial role of antioxidants on clinical outcomes and erythrocyte antioxidant parameters in rheumatoid arthritis patients," International Journal of Preventive Medicine, vol. 5, no. 7, pp. 835-840, 2014.

[15] A. Bala, C. Mondal, P. K. Haldar, and B. Khandelwal, "Oxidative stress in inflammatory cells of patient with rheumatoid arthritis: clinical efficacy of dietary antioxidants," Inflammopharmacology, vol. 25, no. 6, pp. 595-607, 2017.

[16] L. Hagfors, P. Leanderson, L. Sköldstam, J. Andersson, and G. Johansson, "Antioxidant intake, plasma antioxidants and oxidative stress in a randomized, controlled, parallel, Mediterranean dietary intervention study on patients with rheumatoid arthritis," Nutrition Journal, vol. 2, no. 1, p. 5, 2003.

[17] L. T. Berube, M. Kiely, Y. Yazici, and K. Woolf, "Diet quality of individuals with rheumatoid arthritis using the Healthy Eating Index (HEI)-2010," Nutrition and Health, vol. 23, no. 1, pp. 17-24, 2017.

[18] R. L. Prior and G. Cao, "In vivo total antioxidant capacity: comparison of different analytical methods," Free Radical Biology and Medicine, vol. 27, no. 11-12, pp. 1173-1181, 1999. 
[19] V. Katalinic, D. Modun, I. Music, and M. Boban, "Gender differences in antioxidant capacity of rat tissues determined by 2 , $2^{\prime}$-azinobis (3-ethylbenzothiazoline 6-sulfonate; ABTS) and ferric reducing antioxidant power (FRAP) assays," Comparative Biochemistry and Physiology Part C: Toxicology \& Pharmacology, vol. 140, no. 1, pp. 47-52, 2005.

[20] O. Erel, "A novel automated direct measurement method for total antioxidant capacity using a new generation, more stable ABTS radical cation," Clinical Biochemistry, vol. 37, no. 4, pp. 277-285, 2004.

[21] W. Fukuda, A. Omoto, S. Oku et al., "Contribution of rheumatoid arthritis disease activity and disability to rheumatoid cachexia," Modern Rheumatology, vol. 20, no. 5, pp. 439-443, 2014.

[22] J. Chrzczanowicz, A. Gawron, A. Zwolinska et al., "Simple method for determining human serum 2,2-diphenyl-1-picrylhydrazyl (DPPH) radical scavenging activity-possible application in clinical studies on dietary antioxidants," Clinical Chemical Laboratory Medicine, vol. 46, no. 3, 2008.

[23] R. Ilow, O. Królicka, B. Regulska-Ilow, and J. Pluta, "Validation of a food frequency questionnaire for dietary intake estimation among students from Wroclaw," Bromatologia $i$ Chemia Toksykologiczna, vol. 38, pp. 313-320, 2005.

[24] L. Szponar, K. Wolnicka, and E. Rychlik, Album of Photographs of Food Products and Dishes, National Food and Nutrition Institute, Warsaw, 2000.

[25] National Food and Nutrition Institute, "Computer program Dieta 5.0," November 2017, http://www.izz.waw.pl/pl/usugi? $\mathrm{id}=450$.

[26] A. C. Elkan, I. L. Engvall, T. Cederholm, and I. Hafström, "Rheumatoid cachexia, central obesity and malnutrition in patients with low-active rheumatoid arthritis: feasibility of anthropometry, Mini Nutritional Assessment and body composition techniques," European Journal of Nutrition, vol. 48, no. 5, pp. 315-322, 2009.

[27] A. Stavropoulos-Kalinoglou, G. S. Metsios, Y. Koutedakis, and G. D. Kitas, "Obesity in rheumatoid arthritis," Rheumatology, vol. 50, no. 3, pp. 450-462, 2011.

[28] M. Ristow and K. Zarse, "How increased oxidative stress promotes longevity and metabolic health: the concept of mitochondrial hormesis (mitohormesis)," Experimental Gerontology, vol. 45, no. 6, pp. 410-418, 2010.

[29] J. Most, V. Tosti, L. M. Redman, and L. Fontana, "Calorie restriction in humans: an update," Ageing Research Reviews, vol. 39, pp. 36-45, 2017.

[30] E. A. Miles and P. C. Calder, "Influence of marine n-3 polyunsaturated fatty acids on immune function and a systematic review of their effects on clinical outcomes in rheumatoid arthritis," British Journal of Nutrition, vol. 107, no. S2, pp. S171-S184, 2012.

[31] Y. H. Lee, S. C. Bae, and G. G. Song, "Omega-3 polyunsaturated fatty acids and the treatment of rheumatoid arthritis: a meta-analysis," Archives of Medical Research, vol. 43, no. 5, pp. 356-362, 2012.

[32] B. Sundström, I. Johansson, and S. Rantapää-Dahlqvist, "Interaction between dietary sodium and smoking increases the risk for rheumatoid arthritis: results from a nested casecontrol study," Rheumatology, vol. 54, no. 3, pp. 487-493, 2015.

[33] S. L. Sharma, S. A. Chokshi, and C. Chakraborti, "Enzymatic antioxidants, malondialdehyde, and total antioxidant activity as markers of oxidative-stress in arthritis and rheumatoid arthritis," NHL Journal of Medical Sciences, vol. 3, no. 2, pp. 27-31, 2014.

[34] G. Cao and R. L. Prior, "Comparison of different analytical methods for assessing total antioxidant capacity of human serum," Clinical Chemistry, vol. 44, 6 Part 1, pp. 1309-1315, 1998.

[35] A. L. Dawidowicz, D. Wianowska, and M. Olszowy, "On practical problems in estimation of antioxidant activity of compounds by DPPH method (problems in estimation of antioxidant activity)," Food Chemistry, vol. 131, no. 3, pp. 10371043, 2012.

[36] Y. Ozkan, S. Yardým-Akaydýn, A. Sepici, E. Keskin, V. Sepici, and B. Simsek, "Oxidative status in rheumatoid arthritis," Clinical Rheumatology, vol. 26, no. 1, pp. 64-68, 2007.

[37] S. C. Bae, W. J. Jung, E. J. Lee, R. Yu, and M. K. Sung, "Effects of antioxidant supplements intervention on the level of plasma inflammatory molecules and disease severity of rheumatoid arthritis patients," Journal of the American College of Nutrition, vol. 28, no. 1, pp. 56-62, 2009.

[38] J. J. Lee, V. P. Bykerk, G. K. Dresser et al., "Reduction in serum uric acid may be related to methotrexate efficacy in early rheumatoid arthritis: data from the Canadian Early Arthritis Cohort (CATCH)," Clinical Medicine Insights: Arthritis and Musculoskeletal Disorders, vol. 9, article CMAMD.S38092, 2016.

[39] S. Datta, S. Kundu, P. Ghosh, S. De, A. Ghosh, and M. Chatterjee, "Correlation of oxidant status with oxidative tissue damage in patients with rheumatoid arthritis," Clinical Rheumatology, vol. 33, no. 11, pp. 1557-1564, 2014.

[40] L. Zhou, J. T. Feng, L. Zhang, and Y. Kuang, "Clinical significance of serum total oxidant/antioxidant status for the disease activity in active rheumatoid arthritis," International Journal of Clinical and Experimental Pathology, vol. 10, no. 8, pp. 8895-8900, 2017.

[41] K. Zabłocka-Słowińska, S. Płaczkowska, A. Prescha et al., "Serum and whole blood $\mathrm{Zn}, \mathrm{Cu}$ and $\mathrm{Mn}$ profiles and their relation to redox status in lung cancer patients," Journal of Trace Elements in Medicine and Biology, vol. 45, pp. 7884, 2018.

[42] M. D. Bandt, M. Grossin, F. Driss, J. Pincemail, C. BabinChevaye, and C. Pasquier, "Vitamin E uncouples joint destruction and clinical inflammation in a transgenic mouse model of rheumatoid arthritis," Arthritis \& Rheumatism, vol. 46, no. 2, pp. 522-532, 2002.

[43] S.-C. Huang, J. C.-C. Wei, D. J. Wu, and Y.-C. Huang, "Vitamin B6 supplementation improves pro-inflammatory responses in patients with rheumatoid arthritis," European Journal of Clinical Nutrition, vol. 64, no. 9, pp. 10071013, 2010 .

[44] J. Montonen, H. Boeing, A. Fritsche et al., "Consumption of red meat and whole-grain bread in relation to biomarkers of obesity, inflammation, glucose metabolism and oxidative stress," European Journal of Nutrition, vol. 52, no. 1, pp. 337-345, 2013.

[45] S. Hirako, H. J. Kim, Y. Iizuka, M. Nakasatomi, and A. Matsumoto, "Fish oil prevents excessive hepatic lipid accumulation without inducing oxidative stress," Prostaglandins, Leukotrienes and Essential Fatty Acids, vol. 88, no. 5, pp. 365-371, 2013.

[46] R. L. Prior, L. Gu, X. Wu et al., "Plasma antioxidant capacity changes following a meal as a measure of the ability of a food 
to alter in vivo antioxidant status," Journal of the American College of Nutrition, vol. 26, no. 2, pp. 170-181, 2007.

[47] S. B. Lotito and B. Frei, "The increase in human plasma antioxidant capacity after apple consumption is due to the metabolic effect of fructose on urate, not apple-derived antioxidant flavonoids," Free Radical Biology and Medicine, vol. 37, no. 2, pp. 251-258, 2004.

[48] S. Hurst, Z. Zainal, B. Caterson, C. E. Hughes, and J. L. Harwood, "Dietary fatty acids and arthritis," Prostaglandins, Leukotrienes and Essential Fatty Acids (PLEFA), vol. 82, no. 4-6, pp. 315-318, 2010.

[49] R. L. Prior and G. Cao, “Antioxidant capacity and polyphenols components of teas: implications for altering in vivo antioxidant status," Proceedings of the Society for Experimental Biology and Medicine, vol. 220, no. 4, pp. 255-261, 1999.

[50] R. J. Bloomer, "Decreased blood antioxidant capacity and increased lipid peroxidation in young cigarette smokers compared to nonsmokers: impact of dietary intake," Nutrition Journal, vol. 6, no. 1, pp. 39-44, 2007.

[51] V. F. Manfredsdottir, T. Vikingsdottir, T. Jonsson et al., "The effects of tobacco smoking and rheumatoid factor seropositivity on disease activity and joint damage in early rheumatoid arthritis," Rheumatology, vol. 45, no. 6, pp. 734-740, 2006. 


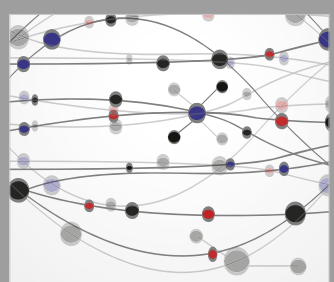

The Scientific World Journal
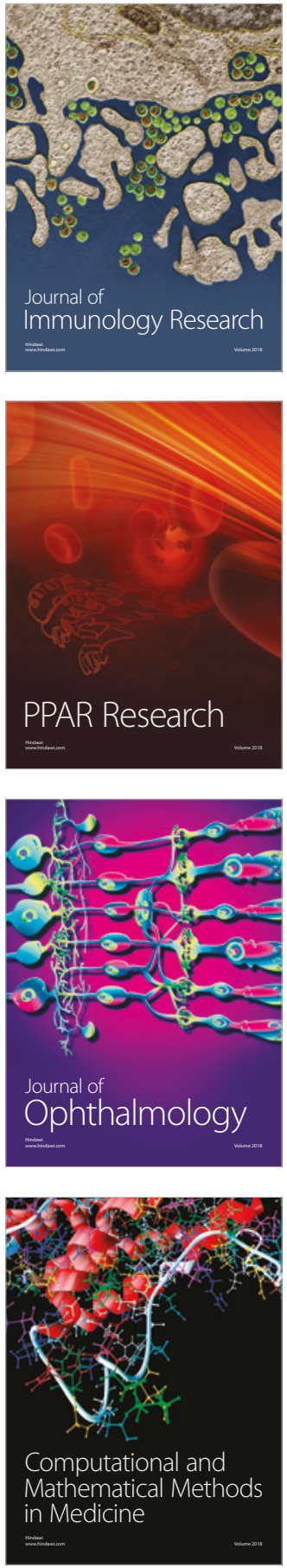

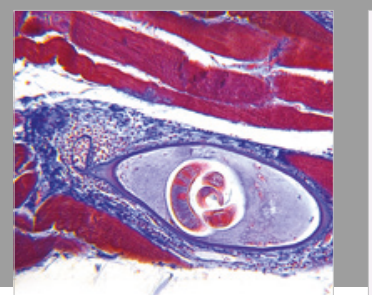

Gastroenterology Research and Practice

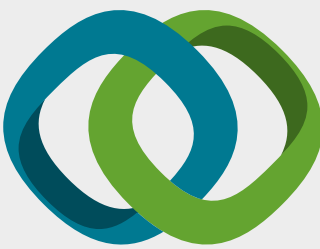

\section{Hindawi}

Submit your manuscripts at

www.hindawi.com
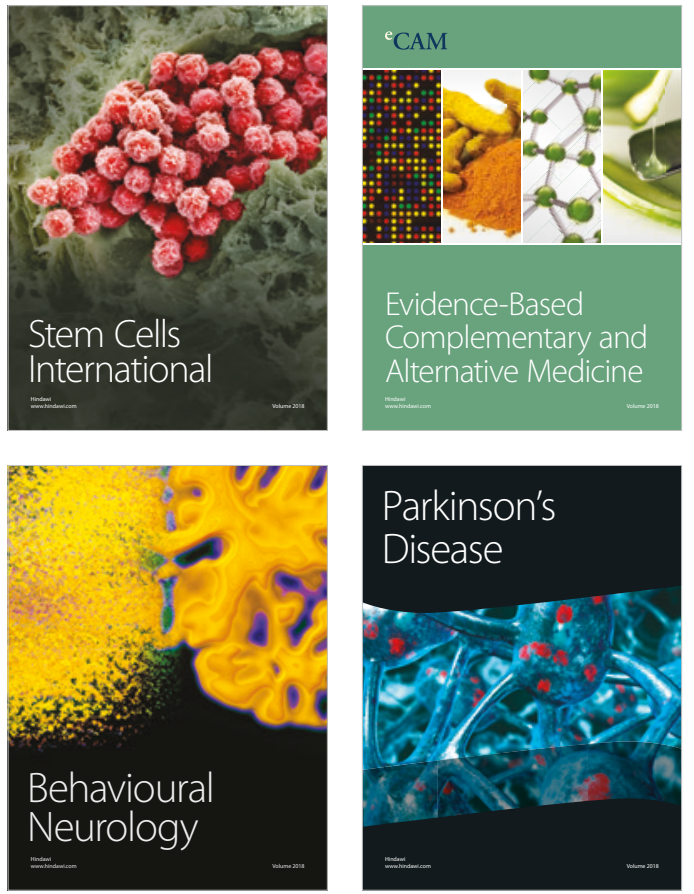

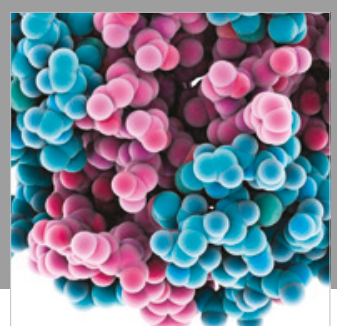

ournal of

Diabetes Research

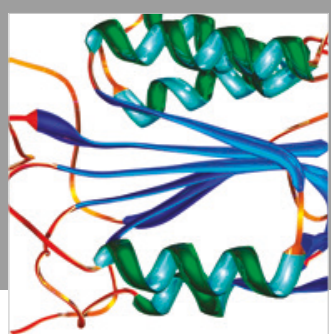

Disease Markers
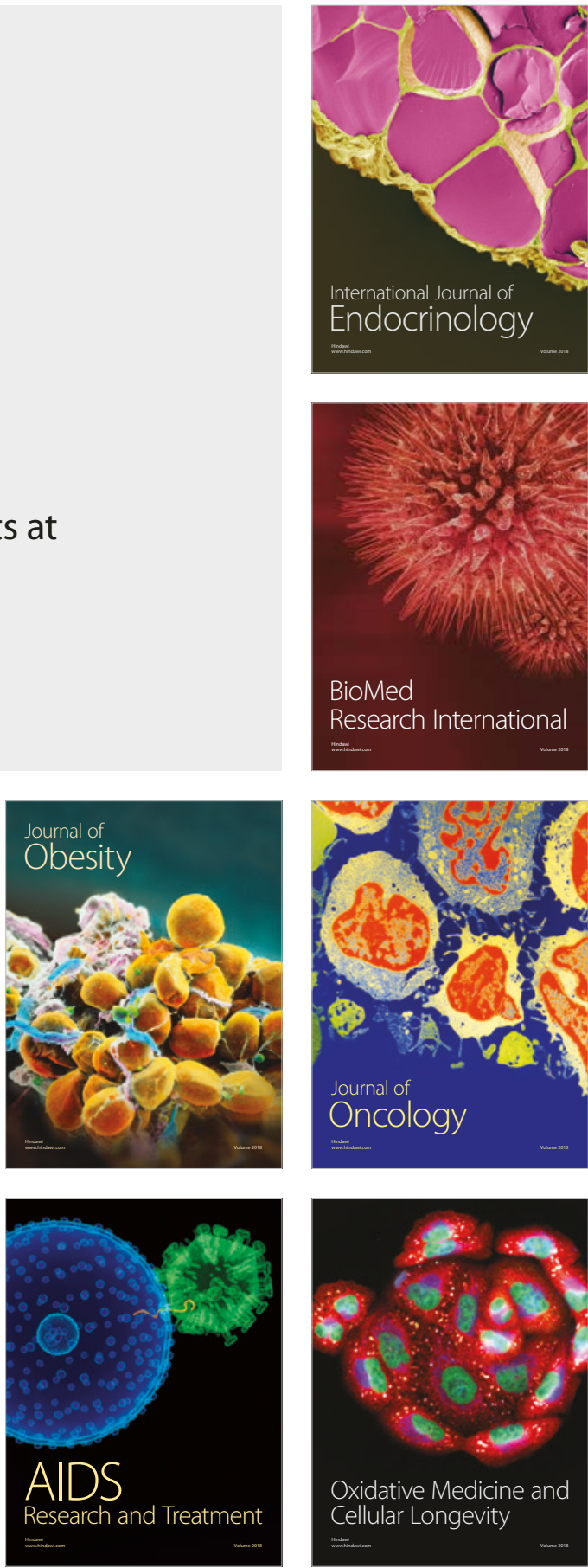